\title{
Message from the New Editor-in-Chief
}

\author{
Hee-Seung Henry Bom ${ }^{1}$ (D)
}

Received: 8 January 2021 / Revised: 13 January 2021 / Accepted: 15 January 2021 / Published online: 2 February 2021

(C) Korean Society of Nuclear Medicine 2021

\section{Dear Readers,}

I am delighted to introduce myself as the new editor-inchief of the Nuclear Medicine and Molecular Imaging. I am succeeding two previous editors, Prof. June-Key Chung (2010-2014) and Prof. Dong Soo Lee (2015-2020). As the official journal of the Korean Society of Nuclear Medicine (KSNM), Nuclear Medicine and Molecular Imaging reflects the growth of nuclear medicine in Korea. Pioneers of KSNM led by late Prof. Munho Lee have started NM from the ruins of the Korean War. The rapid development of NM in Korea was indebted to supports of the International Atomic Energy Agency (IAEA) and of many developed countries including the US and European countries. This is the same now in many developing countries over the world. This year is the 60th anniversary of KSNM. I am planning to overview the experience of KSNM last 60 years in various aspects by review articles published in Nuclear Medicine and Molecular Imaging this year. This overview starts with an essay of our first editor-in-chief, Prof. June-Key Chung [1].

Fortunately, the Society of Nuclear Medicine and Molecular Imaging (SNMMI) selected Korea as the highlight country of this year. Leadership of KSNM and SNMMI as well as leadership of Nuclear Medicine and Molecular Imaging and Journal of Nuclear Medicine are discussing how to make the highlight country program and international collaboration more fruitful. It will be interesting to read coming articles in Nuclear Medicine and Molecular Imaging to observe collaborative activities of KSNM and SNMMI.

Science is the key value of Nuclear Medicine and Molecular Imaging as of other leading journals in this field. As the new editor-in-chief, I am going to continuously invite eminent scientists not only in Korea but all over the globe to the editorial board of Nuclear Medicine and Molecular
Imaging. We welcome various kinds of manuscripts including original articles, reviews, case reports, and letters to the editors from anywhere in the world. By sharing ideas of NM professionals, Nuclear Medicine and Molecular Imaging hopes to be a bridge between not only bench and bedside but also developing and developed countries. As the COVID-19 pandemic continues, many NM clinics and laboratories have difficulties in both patient care and research. Nuclear Medicine and Molecular Imaging also hopes to share experience of confronting challenges in NM community. Communication is another key value of Nuclear Medicine and Molecular Imaging. I hope that our readers enjoy reading articles and news in Nuclear Medicine and Molecular Imaging and giving us comments and opinions. Editors of Nuclear Medicine and Molecular Imaging do our best to make more chances of communication with readers.

\section{Declarations}

Conflict of Interest Hee-Seung Henry Bom declares no conflict of interest.

Ethical Approval and Consent to participate No need for ethical approval and informed consent.

\section{References}

1. Ryoo HG, Suh MS, Paeng JC, Chung JK. Short essay on academic achievement of KSNM during the last 60 years. Nucl Med Mol Imaging. 2021; 55(1).

Publisher's Note Springer Nature remains neutral with regard to jurisdictional claims in published maps and institutional affiliations.

Hee-Seung Henry Bom

henryhsbom@gmail.com

1 Department of Nuclear Medicine, Chonnam National University Hwasun Hospital, Hwasun, Jeonnam 58128, Republic of Korea 